\title{
On-line Titanium Dioxide Nanotube Preconcentration for ICP-MS Determination of Trace Silver in Biological Samples
}

\author{
Xinle Guo, Shizhong Chen', Yan Zhang, and Dengbo Lu \\ College of Chemical and Environmental Engineering, \\ Wuhan Polytechnic University, \\ 68 Xuefu South Road Changqing Garden, Wuhan 430023, P.R. China
}

\section{INTRODUCTION}

Silver is known as a precious and noble metal together with gold and the platinum group elements, and is used widely in various areas. The main features of these elements include rare occurrence in the world, high economic value, and attractive chemical and physical properties (1-3). Silver is introduced into the environment through geochemical and anthropogenic activities. In particular, recent advances in nanotechnology have rapidly increased nano-silver usage in consumer products, ranging from socks, paints, bandages, food containers, and even food supplements (4). The increased release of $\mathrm{Ag}$ into the environment could have toxic effects on aquatic organisms, and may affect human health $(5,6)$. Therefore, the accurate and precise determination of trace and ultratrace Ag in biological and environmental samples is very important for the assessment of its ecological and environmental impact during its production, processing, and usage.

It is well known that inductively coupled plasma atomic emission spectrometry (ICP-AES), inductively coupled plasma mass spectrometry (ICP-MS), and atomic absorption spectrometry (AAS) are still dominant analytical techniques used for precious metal determinations $(6$, 7-9). However, the direct determination of precious metals in geological, biological, and environmental samples by these techniques suffers

\footnotetext{
*Corresponding autbor.

E-mail: chenshizbong62@163.com

Fax: + 862783956442
}

\begin{abstract}
In this study, a novel method is presented for the preconcentration of trace silver using titanium dioxide nanotubes (TDNTs) as a new adsorption material packed into microcolumn prior to the determination by inductively coupled plasma mass spectrometry (ICP-MS).

The adsorption and elution behaviors of silver ion studied on TDNTs were investigated systematically under dynamic conditions. The effects of $\mathrm{pH}$, sample flow rate and volume, elution solution, and interfering ions on the preconcentration and separation of the analytes were examined in detail. The adsorption capacity of TDNTs for Ag was found to be $8.5 \mathrm{mg} \mathrm{g}^{-1}$. Under the optimum conditions, the detection limit $(3 \sigma)$ of this method was $0.021 \mathrm{ng} \mathrm{mL}^{-1}$ for $\mathrm{Ag}$, and the relative standard deviation was $4.5 \%\left(n=9, c=0.5 \mathrm{ng} \mathrm{mL}^{-1}\right)$. This method was applied to the determination of trace $\mathrm{Ag}$ in biological samples with recoveries of $92.0-106 \%$. In order to validate this method, a certified reference material of GBW 07604 Poplar Leaves was analyzed, and the determined values were in good agreement with the certified values.
\end{abstract}

from their very low concentrations, complicated sample matrices, and high matrix content. In order to overcome these problems, an effective separation and preconcentration technique is often required prior to determination. To date, the widely used techniques for the separation and preconcentration of trace/ultra-trace precious metals include fire assay, co-precipitation, solvent extraction, solid phase extraction (SPE), ion exchange, cloud point extraction, electrodeposition, and chromatography (1017). Among these techniques, SPE has been widely used for the separation and preconcentration of trace elements because of its simplicity, high preconcentration factors, rapid phase separation, and ability to be used with different detection techniques. It is worth noting that the sorbent plays a fundamentally crucial role in this technique because the performance of an analytical method is directly related to its effectiveness. Hence, current research in SPE has mainly focused on the development of novel sorbents and the evaluation of their characteristics (18-21).

Recently, nanometer-size material has shown exceptional adsorption capability owing to its small size, large specific surface area, excellent mechanical strength, high chemical stability, and unique electrical properties $(22,23)$. Some nanometer-size substances, such as carbon nanofibers, carbon nanotubes, titanium dioxide nanoparticles, nanopore-size ion imprinted polymer, magnetic mesoporous silica nanoparticles, and gold nanoparticles have been successfully used as solid phase extractants for the preconcentration and separation of trace/ultra-trace substances (22-29). Titanium dioxide nanotubes (TDNTs), as a new and excellent material, have attracted great attention in the fields of photocatalysis and dye-sensitized solar cells. It has been proved and reported in the literature (30) that they have a 
larger surface area than titanium dioxide nanoparticles and carbon nanotubes. In addition, they provide very attractive features such as high chemical stability, durability, corrosion-resistance, are non-toxic and low cost. All of the facts mentioned above reveal to us that TDNTs may be a promising candidate as adsorbers for the preconcentration and separation of different substances. To the best of our knowledge, however, study on the use of TDNTs for the preconcentration, separation, and determination of silver has not been reported in the literature.

The purpose of the present study was to investigate the adsorption properties of $\mathrm{Ag}^{+}$on TDNTs under dynamic conditions, optimize the parameters affecting preconcentration and determination, and propose a novel method using a microcolumn packed with TDNTs coupled to ICP-MS for the preconcentration and determination of trace Ag in biological samples.

\section{EXPERIMENTAL}

\section{Instrumentation}

An X-7 ICP-MS system (Thermo Elemental Corporation, USA) with a concentric nebulizer (Meinhard) was used for analyte determination.
The optimum operating conditions for ICP-MS are given in Table I. A HL-2 peristaltic pump (Shanghai Qingpu Huxi Instrument Factory, P.R. China), coupled to a self-made polytetrafluoroethylene (PTFE) microcolumn $(20 \mathrm{~mm} \times 3.0 \mathrm{~mm}$ i.d.) packed with TDNTs, was used for the preconcentration/ separation process. A minimum length of PTFE tube with an i.d. of $0.5 \mathrm{~mm}$ was used for all connections. The $\mathrm{pH}$ values of the solution were measured with a $\mathrm{pH}$ meter (Thermo Orion Corporation, USA) supplied with a combined electrode. An Ethos TTM microwave digestion device (Milestone, Italy) was used for sample digestion.

\section{Stock Standard Solution and Reagents}

The stock standard solutions (1.0 $\mathrm{mg} \mathrm{mL}^{-1}$ ) of Ag and In were obtained from the National Analysis Center of Iron \& Steel (Beijing, P.R. China). The working solutions were prepared by dilution from the stock solutions. Quantification of the elemental concentration was performed by external calibration with aqueous standard solutions using ${ }^{115}$ In as an internal standard. The TDNTs were synthesized with the hydrothermal method according to the literature (31). All reagents used were ultrapure or

Table I

ICP-MS Operating Parameters

\begin{tabular}{ll}
\hline Plasma Power & $1300 \mathrm{~W}$ \\
Plasma Argon Flow Rate & $14 \mathrm{~L} \mathrm{~min}^{-1}$ \\
Auxiliary Argon Flow Rate & $0.76 \mathrm{~L} \mathrm{~min}^{-1}$ \\
Nebulizer Argon Flow Rate & $0.92 \mathrm{~L} \mathrm{~min}^{-1}$ \\
Sampler Orifice (nickel) & $1.1 \mathrm{~mm}$ \\
Skimmer Orifice (nickel) & $0.7 \mathrm{~mm}$ \\
Acquisition Mode & Peak-jumping \\
Number of Sweep & 100 \\
Dwell Time & $10 \mathrm{~ms}$ \\
Acquisition Time & $40 \mathrm{~s}$ \\
Number of Measurements per Peak & 3 \\
Isotopes & $109 \mathrm{Ag}$ and ${ }^{115} \mathrm{In}$ \\
\hline
\end{tabular}




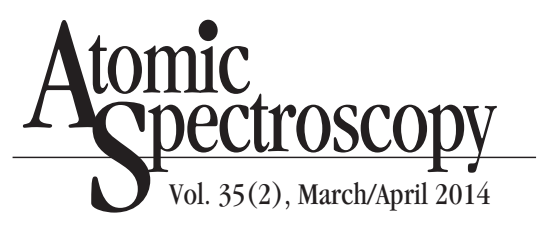

the retained analytes were eluted with $2.0 \mathrm{~mL}$ of $1.0 \mathrm{~mol} \mathrm{~L}^{-1} \mathrm{HNO}_{3}$ solution containing $1.5 \%$ thiourea $\left(\mathrm{H}_{2} \mathrm{NCSNH}_{2}\right)$. The analytes in the effluents were determined by ICPMS. The microcolumn could be used repeatedly after regeneration with $3.0 \mathrm{~mol} \mathrm{~L}^{-1} \mathrm{HNO}_{3}$ solution and deionized water. The recoveries of the analytes were calculated from the ratio of the concentration found by ICP-MS to that of the initial sample.

\section{RESULTS AND DISCCUTION}

\section{Effect of $\mathbf{p H}$}

The $\mathrm{pH}$ of the sample solution is one of the most important parameters which affects the retention of the metal ion on the sorbent. In order to evaluate the effect of $\mathrm{pH}$, a series of sample solutions was adjusted to the $\mathrm{pH}$ range of 1.0-8.0 with $\mathrm{HNO}_{3}$ and $\mathrm{NH}_{3} \cdot \mathrm{H}_{2} \mathrm{O}$, and passed through the microcolumn packed with TDNTs at a given flow rate. The effect of sample solution $\mathrm{pH}$ on the recoveries of the studied ion was investigated according to the recommended procedure. The recoveries were calculated based on the difference between the amounts of the analytes in the starting sample and the solution outflowing from the column. The results shown in Figure 1 indicate that the recoveries (>90\%) for the studied ion were quantitatively obtained in the $\mathrm{pH}$ between 3.0 and 5.0. Therefore, the following experiments were carried out at $\mathrm{pH}$ 4.0 for the studied ion.

\section{Choice of Eluent}

The choice of eluent is very important for coupling a microcolumn preconcentration system to ICP-MS. In order to choose a proper eluent for the retained ion, the studied metal ion was stripped from the TDNTs using $\mathrm{HNO}_{3}$, $\mathrm{H}_{2} \mathrm{NCSNH}_{2}$, and $\mathrm{H}_{2} \mathrm{NCSNH}_{2}+\mathrm{HNO}_{3}$ with different concentrations, respectively. The experimental results showed that $1.0 \mathrm{~mol} \mathrm{~L}^{-1}$ $\mathrm{HNO}_{3}$ solution containing $1.5 \%$ $\mathrm{H}_{2} \mathrm{NCSNH}_{2}$ can accomplish the quantitative elution of $\mathrm{Ag}^{+}$(>90\%) from the TDNTs. In addition, the effect of eluent volume on the recovery of the target ion was also investigated. It was found that the quantitative recoveries ( $>90 \%$ ) could be obtained with $2.0 \mathrm{~mL}$ of $1.0 \mathrm{~mol} \mathrm{~L}^{-1} \mathrm{HNO}_{3}$ solution contain- ing $1.5 \% \mathrm{H}_{2} \mathrm{NCSNH}_{2}$. Thus, $2.0 \mathrm{~mL}$ eluent was adopted for this work.

\section{Effect of Sample Flow Rate}

A 20-mL sample solution was percolated through the column at flow rates varying from 0.3 to $2.0 \mathrm{~mL} \mathrm{~min}^{-1}$ under the optimum operating conditions. The experimental results showed that quantitative recoveries of the studied ion (>90\%) were obtained in the flow rate range of $0.3-1.2 \mathrm{~mL} \mathrm{~min}^{-1}$ (Figure 2). However, the recoveries of the studied ion decreased by further increasing the flow rate above $1.0 \mathrm{~mL} \mathrm{~min}^{-1}$. The reason for this probably is insufficient contact between the studied ion and the adsorbent to reach equilibrium. Thus, a flow rate of $1.0 \mathrm{~mL}$ $\min ^{-1}$ was selected for all subsequent experiments.

\section{Effect of Sample Volume}

The effect of sample volume on the recoveries was investigated to find the ideal volume of sample solution. For this purpose, sample solutions containing $10 \mathrm{ng}$ of the studied ion at volumes between 20 and $250 \mathrm{~mL}$ were prepared and passed through the microcolumn

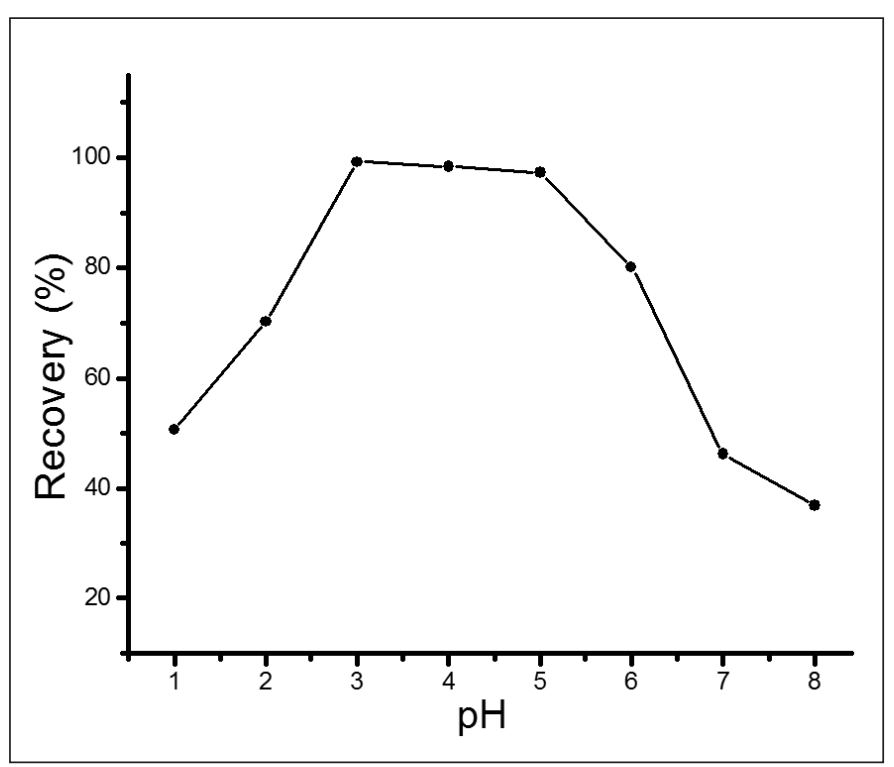

Fig. 1. Effect of $p H$ on recovery of the studied ion. Ag: $2.0 \mathrm{ng} \mathrm{mL}^{-1}$; sample volume: $20 \mathrm{~mL}$.

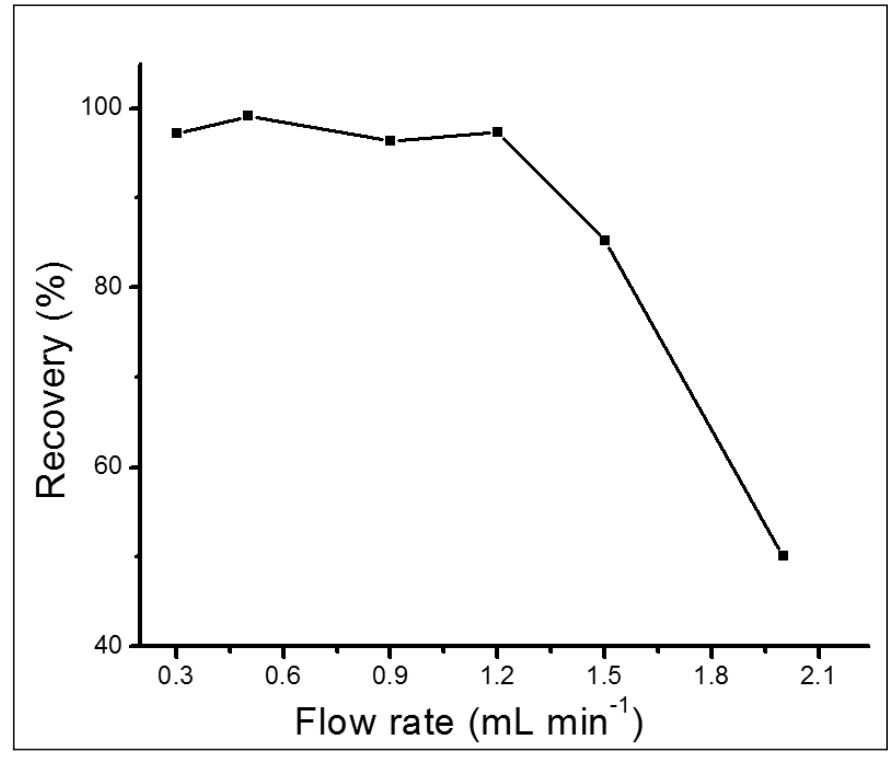

Fig. 2. Effect of sample flow rate on recovery of the studied ion. Ag: $2.0 \mathrm{ng} \mathrm{mL}^{-1}$; sample volume: $20 \mathrm{~mL}$. 
at an optimum flow rate according to the recommended procedure. As can be seen in Figure 3, the studied ion could be recovered quantitatively (>90\%) up to $150 \mathrm{~mL}$ of sample solution. In other words, the ideal sample volume is less than $150 \mathrm{~mL}$. Since the adsorbed ions can be eluted with $2.0 \mathrm{~mL}$ of $1.0 \mathrm{~mol} \mathrm{~L}^{-1} \mathrm{HNO}_{3}$ solution containing $1.5 \% \mathrm{H}_{2} \mathrm{NCSNH}_{2}$, an enrichment factor of 75 was achieved in this work.

\section{Effect of Interfering Ions}

In order to apply this method to real samples, the effect of potential interference ions in biological samples on the preconcentration and determination of the analytes were examined. In the experiments, the solution of $3.0 \mathrm{ng} \mathrm{mL}^{-1}$ target ion containing the added interfering ions was tested according to the recommended procedure under the optimum conditions. The tolerance limit of the coexisting ions is defined as the largest amount resulting in silver recovery of less than $90 \%$. The experimental results are summarized in Table II. As can be seen, the presence of major cations and anions has no obvious influence on the preconcentration and determination of the studied ion under the selected conditions.

\section{Adsorption Capacity}

The adsorption capacity was investigated by a method provided in the literature (32). Aliquots of $20 \mathrm{~mL}$ of a series of concentrations (1.0-6.0 $\mu \mathrm{g} \mathrm{mL}^{-1}$ ) were adjusted to the appropriate $\mathrm{pH}$, then preconcentrated and eluted. The amount of metal ions adsorbed at each concentration level was determined. Breakthrough curves were obtained by plotting the metal ion concentrations $\left(\mu \mathrm{g} \mathrm{mL} \mathrm{m}^{-1}\right)$ versus the milligrams of metal ions adsorbed on per gram of adsorbent. The adsorption capacity calculated from the breakthrough curve was $8.5 \mathrm{mg} \mathrm{g}^{-1}$ for Ag.

\section{Analytical Performance Characteristics}

The analytical performance characteristics of this method, including precision, linear range of calibration curve, and detection limits, were carried out under the optimum experimental conditions. The detection limits of Ag, based on three times the standard devia-

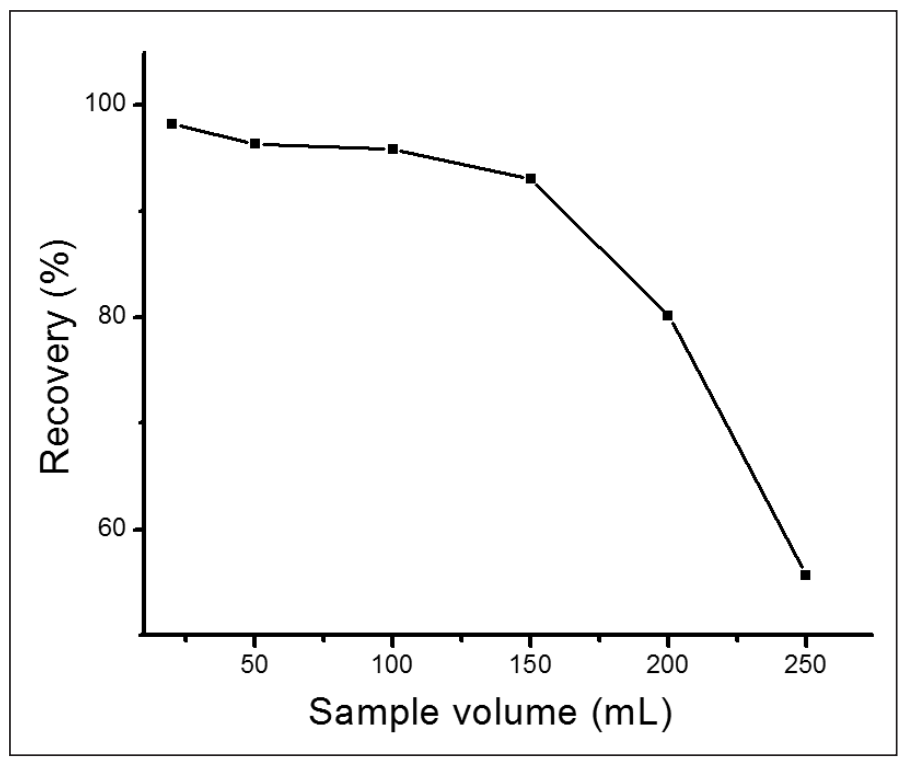

Fig. 3. Effect of sample volume on recovery of the studied ion. Ag: $10 \mathrm{ng}$ tion of the blank solution, was found to be $0.021 \mathrm{ng} \mathrm{mL}^{-1}$. The relative standard deviation was $4.5 \%$ for the nine determinations of $0.5 \mathrm{ng} \mathrm{mL}^{-1}$ of $\mathrm{Ag}$. The linear range of this method was from 0.1 to $100 \mathrm{ng} \mathrm{mL}^{-1}$ with the correlation coefficient better than 0.9991 .

\section{Application of the Method}

In order to identify the accuracy of this method, a biological sample of human hair and the certified reference material GBW 07604 Poplar Leaves (obtained from the Institute of Geophysical and Geochemical Prospecting, Langfang, P.R. China) were analyzed under the optimum conditions. The obtained results are summarized in Table III. As can be seen, the determined values were in good agreement with the certified values, and the recoveries were in the range of $92.0-106 \%$.

TABLE II

Effect of Potential Interfering Ions

\begin{tabular}{lr}
\hline $\begin{array}{l}\text { Coexisting } \\
\text { Ion }\end{array}$ & $\begin{array}{c}\text { Concentration } \\
\text { Ratio }\end{array}$ \\
\hline $\mathrm{Na}^{+}, \mathrm{K}^{+}$ & 20,000 \\
$\mathrm{Ca}^{2+}, \mathrm{Mg}^{2+}$ & 10,000 \\
$\mathrm{Zn}^{2+}, \mathrm{Fe}^{3+}, \mathrm{Al}^{3+}$ & 500 \\
$\mathrm{SO}_{4}{ }^{2-}, \mathrm{SiO}_{3}{ }^{2-}, \mathrm{PO}_{4}^{3-}$ & 5000 \\
\hline${ }^{3}$ Concentration ratio: \\
Foreign ion/determined ion.
\end{tabular}

TABLE III

Analytical Results of Trace Silver in Biological Samples

\begin{tabular}{lcccc}
\hline Sample & $\begin{array}{c}\text { Added } \\
\left(\mu \mathrm{g} \mathrm{g}^{-1}\right)\end{array}$ & $\begin{array}{c}\text { Found }^{\mathrm{a}} \\
\left(\mu \mathrm{g} \mathrm{g}^{-1}\right)\end{array}$ & $\begin{array}{c}\text { Certified } \\
\left(\mu \mathrm{g} \mathrm{g}^{-1}\right)\end{array}$ & $\begin{array}{c}\text { Recovery } \\
(\%)\end{array}$ \\
\hline Human Hair & 0 & $0.025 \pm 0.003$ & - & - \\
& 0.05 & $0.078 \pm 0.006$ & - & 106 \\
& 0.1 & $0.126 \pm 0.011$ & - & 101 \\
Poplar Leaves & 0.2 & $0.219 \pm 0.015$ & - & 97.0 \\
& 0.05 & $0.011 \pm 0.001$ & $0.013^{\mathrm{b}}$ & - \\
& 0.1 & $0.106 \pm 0.008$ & - & 92.0 \\
& 0.2 & $0.208 \pm 0.013$ & - & 98.5 \\
\hline
\end{tabular}

${ }^{a}$ Mean value \pm standard deviation, $n=3$.

${ }^{\mathrm{b}}$ Reference value. 


\section{CONCLUSION}

In this work, the preconcentration and separation of silver in biological samples is described using a microcolumn loaded with titanium dioxide nanotubes (TDNTs), combined with inductively coupled plasma mass spectrometry (ICP-MS) analysis. The adsorption behavior of the analytes on the TDNTs was investigated systematically. The studied ion was retained on the TDNTs in the $\mathrm{pH}$ range of 3.0-5.0 and desorbed quantitatively with $2.0 \mathrm{~mL}$ of $1.0 \mathrm{~mol} \mathrm{~L}^{-1} \mathrm{HNO}_{3}$ solution containing $1.5 \% \mathrm{H}_{2} \mathrm{NCSNH}_{2}$. In addition, no carryover was observed in the next analysis. An enrichment factor of 75 was achieved. It can, therefore, be expected that the TDNTs have great potential as an adsorbent for the preconcentration and determination of trace/ultra-trace elements in real samples.

\section{ACKNOWLEDGMENTS}

The authors are grateful to the Nature Science Foundation and the Education Department Foundation of Hubei Province in China for supporting this project.

$\overline{\text { Received January 7, } 2014 .}$

\section{REFERENCES}

1. C. E. Garrett and K. Prasad, Adv. Synth. Catal. 346, 889 (2004).

2. M. Imamoglu and V. Gunes, At. Spectrosc. 33(6), 205 (2012).

3. J. N. Armor, J. Membr. Sci. 147, 217 (1998).

4. E. Navarro, F. Piccapietra, B. Vagner, F. Marconi, R. Kaegi, and N. Odzak, Environ. Sci. Technol. 42, 8959 (2008).

5. A. Bradford, R.D. Handy, J.W. Readman, A. Atfield, and M. Muhling, Environ. Sci. Technol. 43, 4530 (2009).

6. Y. Luo, E. Dabek-Zlotorzynska, V. Celo, D.C.G. Muir, and L. Yang, Anal. Chem. 82, 3922 (2010).

7. S.K. Gupta, S.K. Thulasidas, N. Goyal, and S.V. Godbole, At. Spectrosc. 34(3), 104 (2013).

8. A.R. Jacobson, M.B. Mcbride, P. Baveye, and T.S. Steenhuis, Sci. Total Environ. 345, 191 (2005).

9. X. Cheng, S. Chen, X. Wang, and C. Liu, At. Spectrosc. 31(3), 75 (2010).

10. R. Parijat, B. Vysetti, S. Sariput, K.S.V. Subramanyam, M. Satyanarayan, K. Vani, and K. Srivalli, At. Spectrosc. 31(2), 35 (2010).

11. M. Gros, J.P. Lorand, and A. Luguet, Chem. Geol. 185(3-4), 179 (2002).

12. A.R. Ghiasvand, F. Moradi, H. Sharghi, and A.R. Hasaninejad, Anal. Sci. 21(4), 387 (2005).

13. M. Imamoglu and S. Albayrak, At. Spectrosc. 33(1), 30 (2012).

14. B.O. Catalina, S.R. Fuensanta, and C.P.J. Manuel, Microchim. Acta 158(1-2), 103 (2007).

15. J.I. Manzoori, H. AbdolmohammadZadeh, and M. Amjadi, Microchim. Acta 159, 71 (2007).

16. M. Konecna and J. Komarek, Spectrochim. Acta Part B 62, 283 (2007).

17. L. Sommer and R. Vlasankova, Chromatogr. 52(11-12), 692 (2000).
18. V.A. Lemos, L.S.G. Teixeira, M.D.A. Bezerra, A.C.S. Costa, J.T. Castro, L.A.M. Cardoso, D.S.D. Jesus, E.S. Santos, P.X. Baliza, and L.N. Santos, Appl. Spectrosc. Rev. 43, 303 (2008).

19. V. Camel, Spectrochim. Acta Part B 58, 1177 (2003).

20. W. Tian and Z. Fan, At. Spectrosc. 33(1), 36 (2012).

21. C. Duran, D. Ozdes, A. Gundogdu, M. Imamoglu, and H.B. Senturk, Anal. Chim. Acta 75, 688 (2011).

22. Y. Hu, J. Pan, K. Zhang, H. Lian, and G. Li, TrAC Trends Anal. Chem. 43, 37 (2013).

23. K. Pyrzynska, TrAC Trends Anal. Chem. 43, 100 (2013).

24. F. Shakerian, S. Dadfarnia, A. Mohammad, and H. Shabani, Food Chem. 134(1), 488 (2012).

25. Y. He, S. Chen, X. Zhou, and X. Wang, At. Spectrosc. 33(4), 117 (2012).

26. M. Acosta, M. Savio, M.C. Talio, M.L. Ferramola, R.A. Gil, and L.D. Martinez, Microchem. J. 110, 94 (2013).

27. C.Y. Li, L.G. Chen, and W. Li, Microchim. Acta 180(11-12), 1109 (2013).

28. F. Aboufazeli, H.R.L.Z. Zhad, O. Sadeghi, M. Karimi, and E. Najafi, Food Chem. 141(4), 3459 (2013).

29. G. Wang, X. He, F. Zhou, Z. Li, B. Fang, X. Zhang, and L. Wang, Food Chem. 135(2), 446 (2012).

30. S. Chen, Y. He, and D. Lu, At. Spectrosc. 34(3), 73 (2013).

31. Q. Wang, J. Tao, L. Weng, S. Song, and H. Tao, Devel. Appl. Mater. 5, 9 (2004).

32. A. Maqieira, H. A. M. Elmahadi, and R. Puchades, Anal. Chem. 66, 3632 (1994). 